\title{
A Typology-Based Approach to Tracing-App Adoption During the COVID-19 Pandemic: The Case of the SwissCovid App
}

\author{
SARAH GEBER \\ THOMAS N. FRIEMEL \\ University of Zurich, Switzerland
}

\begin{abstract}
Contact tracing technology has been introduced in many countries as part of the COVID-19 containment strategy. However, research indicates that current adoption rates are too low for tracing apps to be effective. To address the complexity of app adoption, a typology-based approach is presented that differentiates between refusers who generally reject app adoption, ditherers who hesitate to adopt the app, adopters who have downloaded and activated the app, and de-adopters who had installed the app but later uninstalled it. A national online survey of $N=1,535$ participants in Switzerland revealed significant differences among these groups of people regarding their perceptions about app-related benefits and costs, knowledge about data handling in technology, and app-related opinion leadership. The results indicate that communication strategies that aim to enhance the rate of app adoption should focus on ditherers and adopters; the former are the most promising target group for behavioral change efforts, and the latter seem to be the best means to reach out to this promising group.
\end{abstract}

Keywords: digital contact tracing, technology adoption, diffusion, privacy calculus, opinion leadership, COVID-19

Sarah Geber: s.geber@ikmz.uzh.ch

Date submitted: 2020-12-23

Copyright (C) 2021 (Sarah Geber, Thomas N. Friemel). Licensed under the Creative Commons AttributionNonCommercial-NoDerivatives 4.0 International Public License. Available at: http://journalqd.org 
In 2020, app-based contact tracing was introduced in several countries as part of the COVID-19 containment strategy (Kahn, 2020). These apps are aimed at controlling the pandemic while, at the same time, allowing the economic, political, and social system to recover. The primary objective for contact tracing apps is to stop the spread of COVID-19 by complementing the conventional tracing of transmission chains. However, research suggests that app adoption by about 60 percent of the population is necessary for such technologies to reach their full effectiveness (Ferretti et al., 2020; Hinch et al., 2020).

The promising potential of tracing apps in containing the pandemic and the need for a high rate of adoption stimulated research on tracing-app adoption worldwide. Most of this research was conducted before the release of contact tracing apps to support the introduction of these technologies. Generally, these studies indicate a high willingness among respondents to adopt contact tracing apps. For example, about $80 \%$ of respondents in Italy and France (Altmann et al., 2020), two-thirds in the US (Hargittai et al., 2020), and $60 \%$ in the UK (Bachtiger et al., 2020; see also O'Callaghan et al., 2020; Walrave et al., 2020 ) were willing to adopt these apps. However, surveys that examined app adoption after the release of the technology found that only about two fifths of respondents adopted the apps (Abuhammad et al., 2020; Thomas et al., 2020). These numbers indicate a gap between respondents' claimed intention and actual adoption.

The present study complements this research with a typology-based approach to app adoption based on a national online survey conducted one week after the release of the app in Switzerland. This approach allows us to consider app adoption not as a binary phenomenon (yes/no) but as a complex process that encompasses decisions that have not yet been made as well as those that have been revised (e.g., Straub, 2009; Wisdom et al., 2014). We differentiate between (1) refusers who are unwilling to adopt the app, (2) ditherers who have not currently installed the app but show some willingness to adopt it in the future, (3) adopters who have installed and activated it on their phones, and (4) deadopters who had installed the app but later uninstalled it. Complementary to the predominant predictor-driven perspective in current tracing app research (e.g., Kaspar, 
2020; Sharma et al., 2020; Walrave et al., 2020), we will not predict app adoption but describe the distinct types of app adopters with regard to their perceptions about app-related benefits and costs, their knowledge about data handling in technology, and their app-related opinion leadership. The quantitative description along these dimensions will result in unique profiles for different types of adopters. These profiles are particularly informative for strategic communication efforts that aim to increase app adoption.

\section{A Typology-Based Approach to Tracing-App Adoption}

\section{The Swiss Covid App}

The typology-based approach to app adoption is applied to the introduction of the tracing app in Switzerland. The SwissCovid app uses Bluetooth technology to exchange randomly generated keys with other activated apps that are within $1.5 \mathrm{~m}$ for at least 15 minutes. If an app user tests positive for COVID-19, the user will receive a code from the health authorities that needs to be entered in the app to anonymously alert all users who have been in close contact with the infected person (Federal Statistical Office, 2020). There is empirical evidence that the SwissCovid app reaches exposed contacts, who then test positive for COVID-19, indicating that the app is an effective tool for controlling the spread of COVID-19 (Salathé et al., 2020).

Similar to other contact tracing apps introduced worldwide (Kahn, 2020), the SwissCovid app follows the principle of "privacy by design" (Cavoukian, 2010), meaning that privacy and security protections are built into the design of the technology to ensure data security (rather than only relying on responsible use). The app does not collect location data (as it is built on Bluetooth technology); it stores proximity data decentralized on users' smartphones, deletes the data after 14 days, and minimizes the accessibility of data to public health authorities. Only in cases of a test-confirmed COVID-19 infection and user consent, encrypted information will be sent to a central server (Federal Office of Public Health, 2020). 
The SwissCovid app was released on June 25, 2020. Its use is voluntary, which is guaranteed by law. In line with results from a survey in April 2020 that revealed that more than $70 \%$ of Swiss are willing to install the apps (Hargittai \& Thouvenin, 2020), data from the Federal Statistical Office (2020) document a fast diffusion of the adoption of the app in the Swiss population during the first week after its release. Figure 1 illustrates that the numbers of downloads and active apps steadily increased in the first days. However, after seven days, the numbers of active apps started to stagnate at about one million. However, this is only a rough and conservative estimate because the data-protection measures do not allow any identification and differentiation between users. Considering the two statistics, app users during this period likely comprised $12-20 \%$ of the population, which is below the envisioned penetration.

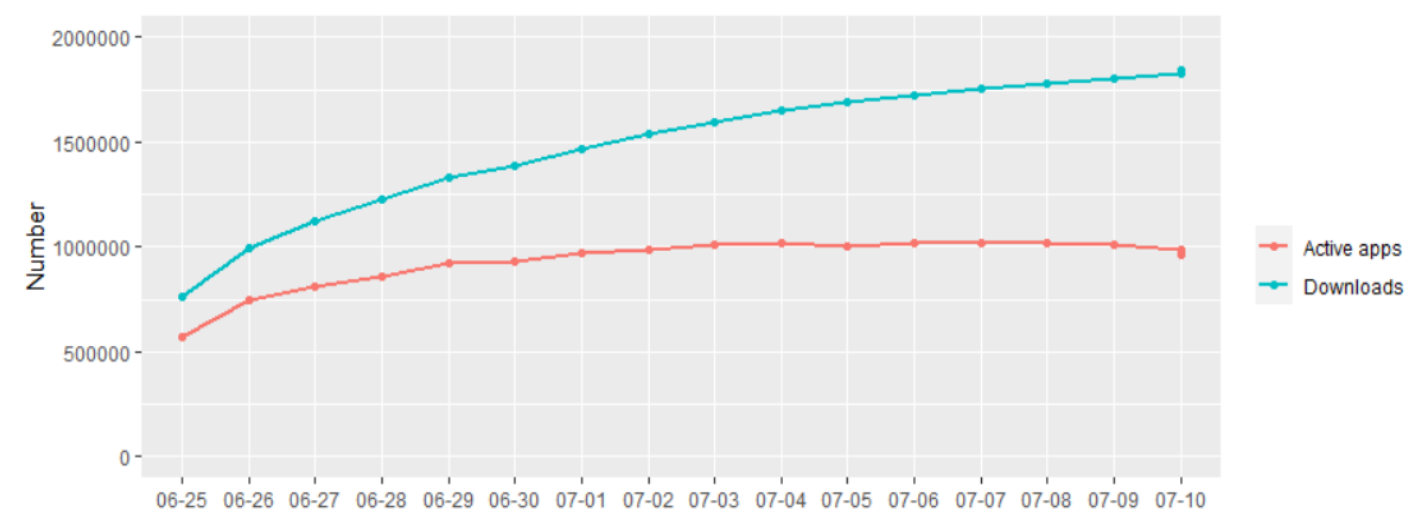

Figure 1. Numbers of active apps and downloads after the release of the SwissCovid app.

\section{A Typology of App Adoption}

In this paper, the adoption and non-adoption of the SwissCovid app after the first week of its release is comprehensively examined. Adoption is defined as having the tracing app installed and activated on the smartphone. Following the technology adoption literature and the understanding of app adoption as a complex process (e.g., Straub, 2009; Wisdom et al., 2014), we differentiate between people who generally refuse to adopt the app 
(refusers), hesitate to adopt the app (ditherers), downloaded and activated the app (adopters), and uninstalled the app after initital installation (de-adopters). This typology allows us to go beyond a binary understanding of app adoption as a yes/no decision because it acknowledges the temporal dimension of technology adoption on the individual level. More concretely, covering individual stages in the adoption process, it considers that there are people who have not yet made a decision (ditherers) and people who have revised their decision on adoption (de-adopters), in addition to people who reject the adoption of the app (refusers) and people who adopt the app (adopters). These types of people have "unique (but malleable) perceptions of technology" (Straub, 2009, p. 626) based on their expectations and experiences related to their stages in the adoption process. Thus, the present typology-based approach to app adoption is theory-driven, and the four types are pre-defined in line with the technology adoption process.

We examine adoption types with regard to their perceptions about the benefits of public health and costs of data misuse, their knowledge about data handling in technology, and their app-related opinion leadership. These dimensions will be particularly insightful from a strategic communication perspective. First, the examination of the benefit-cost assessments of the types may inform the design of effective messages for different target groups. Second, the investigation of the knowledge of members of each type will allow us to distinguish between uninformed and knowledge-driven app-user concerns (Nowak \& Phelps, 1992) and help determine to what extent further information is needed to increase app adoption. Third, the examination of opinion leadership aids in the identification of people that can be addressed as agents of change to ultimately increase the rate of app adoption in the population (Valente \& Davis, 1999).

Perceived health benefits and perceived costs of data misuse. The benefit of tracing technologies on public health and the privacy concerns linked with contact tracing have spurred an intense public debate around the use of contact tracing apps (Guinchard, 2020; Lapolla \& Lee, 2020; Sweeney, 2020). Thus, from a user perspective, the question of app adoption may appear as a "trade-off between privacy and public benefit" (Hargittai 
et al., 2020, para. 14; see also Kaptchuk et al., 2020; Redmiles, 2020). Such cost-benefit assessments that include the disclosure of personal information have been extensively investigated in the tradition of the privacy calculus model (Keith et al., 2013; Laufer \& Wolfe, 1977). According to this model, users are more likely to share personal information when the benefits of the transaction outweigh the risks (Dinev \& Hart, 2006), such as in the present case, when the perceived health benefits are higher than the perceived risk of data misuse (Hassandoust et al., 2020). Notably, previous research on app adoption reveals that both perceptions about the effectiveness of the app as a public health measure and about data misuse play an important role in the adoption process (Bachtiger et al., 2020; Hassandoust et al., 2020; O'Callaghan et al., 2020; Redmiles, 2020; Walrave et al., 2020; Wyl, Höglinger, et al., 2020).

Knowledge about data handling on the app. A thorough understanding of users' privacy concerns requires an examination of the knowledge that underlies those concerns (Nowak \& Phelps, 1992). In the online privacy literature, knowledge about privacy risks is referred to as privacy literacy (Baruh et al., 2017). The idea behind this concept is that people are concerned about their privacy when using digital media but lack privacy literacy - that is, knowledge on how to protect their data - to behave accordingly (Trepte et al., 2015). In the context of tracing apps, it can be assumed that a high amount of knowledge on data handling would support app adoption given the amount of privacy measures implemented in the design of such technologies.

App-related opinion leadership. Technology adoption is inherently linked to the concept of opinion leadership (Rogers, 2002; Wisdom et al., 2014). Opinion leadership has been applied in diffusion of innovations models to explain innovation spread within and between communities (Rogers, 1995, 2002). Opinion leaders are "people who influence the opinions, attitudes, beliefs, motivations, and behaviors of others" (Valente \& Pumpuang, 2006, p. 881). They are particularly knowledgeable in their field of expertise (Trepte \& Scherer, 2010) and try to convince others based on their own opinions (Geber, 2019). Their social influence is not primarily rooted in prominence or in high 
socioeconomic status but in their recognition as experts in their fields (Katz \& Lazarsfeld, 1955; Weimann, 1994). Opinion leaders can eliminate barriers to change and increase the rate of diffusion of innovation (Valente \& Davis, 1999).

\section{Research Question}

To gain a profound understanding of the four different types of app adoption, our typology-based approach seeks to explore differences and similarities between refusers, ditherers, adopters, and de-adopters based on the aforementioned dimensions. The quantitative multidimensional description of the four types will result in unique profiles that are particularly informative for strategic communication efforts. Hence, the following research question is formulated:

RQ: How do refusers, ditherers, adopters, and de-adopters differ with regard to their perceptions about the app's health benefits and costs of data privacy, their knowledge about data handling on the app, and their app-related opinion leadership?

\section{Methods}

\section{Data Collection and Sample}

To answer this research question, we used data from a national online survey based on an online access panel in Switzerland. The data collection started on July 1, one week after the release of the app in Switzerland and ended on July 11; a total of $N=1,535$ participants completed the survey. Switzerland has different language regions: the Germanspeaking region in the north, east, and center of the country; the French region in the west; and the Italian region mostly represented by the southern Canton of Ticino. In order to represent all language regions, the sample was quoted for age, gender, and language region. More specifically, the sample was cross-stratified for these variables, meaning that the proportions of groups defined across all three variables (e.g., females aged 14-29 from the 
German-speaking part of Switzerland) were based on data from the Federal Statistical Office (2019) and that the sampling was based on these proportions. Table 1 presents the targeted and actual cross-quotas of gender, age, and language region; it demonstrates that no post-hoc weighting of the data was necessary as the sample's distributions reflect properly pre-defined quotas. About $49.7 \%$ of the respondents are female, and the mean age is $46.9(S D=17.6$; $\operatorname{Min}=18, \operatorname{Max}=85)$. Additionally, $70.1 \%$ of the respondents live in the German-speaking region, $22.9 \%$ in the French-speaking region, and $7.0 \%$ in the Italianspeaking region of Switzerland.

Table 1. Target and Actual Quotas of Gender, Age, and Language Region.

\begin{tabular}{|c|c|c|c|c|c|c|}
\hline Age & & $14-29$ & $30-44$ & $45-59$ & $60-85$ & Total \\
\hline \multirow{3}{*}{ Female } & $\begin{array}{l}\text { German-speaking } \\
\text { Switzerland }\end{array}$ & $119 / 115$ & $130 / 127$ & $141 / 140$ & $152 / 151$ & $542 / 533$ \\
\hline & $\begin{array}{l}\text { French-speaking } \\
\text { Switzerland }\end{array}$ & $39 / 39$ & $43 / 43$ & $46 / 45$ & $50 / 49$ & $178 / 176$ \\
\hline & $\begin{array}{l}\text { Italian-speaking } \\
\text { Switzerland }\end{array}$ & $12 / 12$ & $13 / 13$ & $14 / 13$ & $15 / 16$ & $54 / 54$ \\
\hline \multirow{3}{*}{ Male } & $\begin{array}{l}\text { German-speaking } \\
\text { Switzerland }\end{array}$ & $119 / 116$ & $141 / 140$ & $141 / 143$ & $141 / 144$ & $542 / 543$ \\
\hline & $\begin{array}{l}\text { French-speaking } \\
\text { Switzerland }\end{array}$ & $39 / 39$ & $46 / 43$ & $46 / 47$ & $46 / 47$ & $177 / 176$ \\
\hline & $\begin{array}{l}\text { Italian-speaking } \\
\text { Switzerland }\end{array}$ & $12 / 12$ & $14 / 14$ & $14 / 14$ & $14 / 13$ & $54 / 53$ \\
\hline Total & & $340 / 333$ & $387 / 380$ & $402 / 402$ & $418 / 420$ & $1,547 / 1,535$ \\
\hline
\end{tabular}

Note. Targeted $n$ /actual $n$. 


\section{Measures}

For some measures, we were not able to adopt questions from previous studies due to the novelty and the specificity of the topic (i.e., tracing technology adoption during a pandemic). To ensure the quality of the measures, we discussed our questions with experts from the Federal Office of Public Health, did extensive pretesting in our research group and with students, and pretested the survey with laypersons with different sociodemographic profiles, particularly in terms of understanding.

Adoption types. The adoption types were identified based on two questions. First, participants were asked a question about their current adoption, that is, whether they had installed and were currently using the contact tracing app ("Do you currently have the federal tracing app [SwissCovid app] installed on your smartphone, and do you use it?"). The following response options were provided: $1=$ no, because I do not have a smartphone ( $n=55), 2=n o$, because I haven't installed it (yet) $(n=633), 3=n o$, because I've uninstalled it already $(n=32), 4=$ yes, but I have deactivated it $(n=29), 5=y e s$, and I use it $(n=786)$. Second, we examined the intentions of participants who indicated that they did not have the app currently installed (adoption $=2$ ), that is, how likely they were to install and use the app in the future on a scale ranging from $1=$ very unlikely to $5=$ very likely ("How likely do you think it is that you will install and use the tracing app in the future?"; $M=2.57, S D=1.38$ ). People who did not have a smartphone ( $n=55$; adoption $=$ 1) were excluded from the analysis, resulting in a final sample of $n=1,480$. The other respondents were classified as refusers, those who had not yet installed the app and had no intentions of doing so $(n=203$; adoption $=2$ and intention $=1)$, ditherers who had not yet installed the app but intended to do so $(n=430$; adoption $=2 \&$ intention $>1)$, adopters who had installed the app and used it ( $n=786$; adoption $=5)$, and de-adopters who had installed the app in the past but uninstalled or deactivated it $(n=61$; adoption $=3$ or 4$)$.

Perceived health benefits and perceived costs of data misuse. To account for the fact that people may perceive a variety of interrelated yet distinct health-related benefits 
and privacy-related costs (Redmiles, 2020), we assessed benefits and costs using several items, each on a scale from $1=$ do not agree at all to $5=$ fully agree. Regarding health benefits, we collected data on the following three aspects: (1) individual health, assessed by the item "When I use the tracing app, it helps me detect a possible infection early" ( $M$ $=3.72, S D=1.2)$; (2) health of the personal social context, covered by the item "When I use the tracing app, it helps me get tested early and protect people around me." $(M=3.83$, $S D=1.19$ ); (3) public health, assessed by the item "When I use the tracing app, I help limit the spread of the virus in the Swiss population" $(M=3.92, S D=1.18)$. To evaluate the cost of data misuse, we differentiated between (1) the perceived risk of data misuse ("There is a big risk that my data will be misused when I use the tracing app"; $M=2.4, S D=1.27$ ); (2) the likelihood of data misuse ("It is likely that the tracing app is collecting too much data about me"; $M=2.64, S D=1.3$ ); and (3) the severity of data misuse ("If the data collected by the app were misused, there would be serious consequences for me and my privacy"; $M=2.85, S D=1.38$ ).

Knowledge about data handling on the app. Knowledge was measured by three questions relating to different aspects of the data handling on the app. These questions were adopted from a survey commissioned by the Federal Office of Public Health in May 2020 (Bosshardt et al., 2020) and refer to the collection, storage, and accessibility of data; several response options were provided for each question (Table 2). A new variable based on the number of correct responses was computed (only exclusively correct answers were counted). This procedure resulted in a knowledge index that ranged from $0=$ no correct responses to $3=$ three correct responses $(M=1.24, S D=0.96)$. 
Table 2. Measure of Knowledge About Data Handling on the App.

\begin{tabular}{|c|c|c|}
\hline Question & Answer Options & $n(\%)$ \\
\hline \multirow{3}{*}{$\begin{array}{l}\text { What kind of data is } \\
\text { collected with the } \\
\text { tracing app? }\end{array}$} & $\begin{array}{l}\text { a) Close contacts with other people who also } \\
\text { use the app* }\end{array}$ & $1270(75.5 \%)$ \\
\hline & b) Movement data (geographical localization) & $522(35.3 \%)$ \\
\hline & c) Don't know & $76(5.1 \%)$ \\
\hline \multirow{5}{*}{$\begin{array}{l}\text { Where is the data that } \\
\text { is recorded by the } \\
\text { tracing app stored? }\end{array}$} & a) Central computer of the Swiss & $440(27.7 \%)$ \\
\hline & Confederation & \\
\hline & b) Locally on individual smartphones* & $692(46.8 \%)$ \\
\hline & c) Computers distributed around the world & $46(3.1 \%)$ \\
\hline & d) Don't know & $398(26.9 \%)$ \\
\hline \multirow{6}{*}{$\begin{array}{l}\text { Who gets access to } \\
\text { your personal data? }\end{array}$} & a) People working as contact tracers & $382(25.8 \%)$ \\
\hline & $\begin{array}{l}\text { b) The scientific community researching the } \\
\text { pathways of contagion }\end{array}$ & $271(18.3 \%)$ \\
\hline & c) $\mathrm{Me}$ & $581(39.2 \%)$ \\
\hline & d) Authorities/police & $162(10.9 \%)$ \\
\hline & e) Nobody* & $282(19.1 \%)$ \\
\hline & f) Don't know & $315(21.3 \%)$ \\
\hline
\end{tabular}

Note. $n=1,480$; multiple answers possible, *right answer.

App-related opinion leadership. Opinion leadership was measured using four items on a 5 -point frequency scale ranging from $1=$ never to $5=$ very often (Table 3 ). Following the idea of "monomorphic" leadership (Merton, 1949), we define and operationalize opinion leadership as domain-specific leadership as opposed to polymorphic opinion leadership, which refers to people who are influential across a broad range of domains and have certain traits (i.e., personality strength, Noelle-Neumann, 1983; Gnambs \& Batinic, 2011). Specifically, in this study, opinion leadership refers to the tracing app, and its measurement is oriented towards Childers' scale (1986; Geber, 2019). Respondents were asked how often they tried to convince others based on their own opinions, argue for the use of the tracing app, offered information, and were asked for their opinion in 
conversations about the tracing app. The corresponding items are listed in Table 3 and were introduced with the question: "When you think about your exchanges with others on the the tracing app of the Federal Office of Public Health (SwissCovid app; e.g., in person, via (video) phone or messenger applications, such as WhatsApp), how often do the following scenarios occur?" The items were internally consistent, and we computed a mean index.

Table 3. Measure of App-Related Opinion Leadership.

\begin{tabular}{llc}
\hline Item & Mean $(S D)$ & $\alpha$ \\
\hline Index & $2.56(1.17)$ & .86 \\
\hline I argue for the use of the tracing app. & $2.93(1.56)$ & \\
I bring in information about the tracing app. & $2.44(1.36)$ & \\
I try to convince my conversation partners of my opinion. & $2.42(1.38)$ & \\
I am asked for my opinion regarding the tracing app. & $2.44(1.26)$ & \\
\hline
\end{tabular}

Note. $n=1,480 ; \alpha=$ Cronbach's alpha.

\section{Analysis Strategy}

The analysis aimed to test differences between refusers, ditherers, adopters, and deadopters. The Shapiro-Wilk test (Shapiro \& Wilk, 1965) indicated that the measures were not normally distributed in each group, and the Levene test showed that the groups did not have equal variances. Given, further, that the groups differ in their size (ranging from $n_{\text {deadopt }}=61$ to $n_{\text {adopt }}=780$ ), we used the non-parametric Kruskal-Wallis test (Kruskal $\&$ Wallis, 1952) to examine the significance of differences between the four groups. On rejection of the null hypothesis and thus the indication of differences across the groups, the Dunn test with a Bonferroni adjustment (Dunn, 1961) was used to examine the differences between the adoption types. All analyses were run in R (R Core Team, 2019), and plots were created with the ggplot package (Wickham, 2016). 


\section{Results}

To investigate the sociodemographic profiles of participants, we describe the types of adopters in line with the sample's quotas of gender, age, and language region. Table 4 reveals that age is distributed relatively equally across the adoption types, while the proportion of women is comparatively high among the ditherers. The proportion of people from the German-speaking region of Switzerland is relatively high among the adopters and de-adopters. Among the refusers, the proportion of people from the French-speaking region, and among the ditherers, the proportion of the Italian part is higher than in other adoption groups.

Table 4. Gender, Age, and Language Region Distribution of the Types of Adopters.

\begin{tabular}{lllll}
\hline & Refusers & Ditherers & Adopters & De-adopters \\
\hline$n(\%)$ & $203(13.2 \%)$ & $430(28.0 \%)$ & $786(51.2 \%)$ & $61(3.9 \%)$ \\
\hline Females & $52 \%$ & $56 \%$ & $47 \%$ & $43 \%$ \\
\hline Age & $M=45.7$ & $M=46.0$ & $M=47.0$ & $M=41.8$ \\
& $(S D=17.6)$ & $(S D=17.4)$ & $(S D=17.3)$ & $(S D=19.0)$ \\
\hline Language & GE: $59.1 \%$ & GE: $66.7 \%$ & GE: $74.3 \%$ & GE: $77.0 \%$ \\
Region & FR: $35.5 \%$ & FR: $23.3 \%$ & FR: $19.6 \%$ & FR: $18.0 \%$ \\
& IT: $5.4 \%$ & IT: $10.0 \%$ & IT: $6.1 \%$ & IT: $4.9 \%$ \\
\hline
\end{tabular}

Note. $N=1,535$.

There are significant differences among refusers, ditherers, adopters, and deadopters in all dimensions being studied: benefit/cost perceptions, knowledge, and opinion leadership. Figure 2 illustrates the differences with regard to the perceptions of individuals from each type about the public health benefits and the costs of data misuse. 

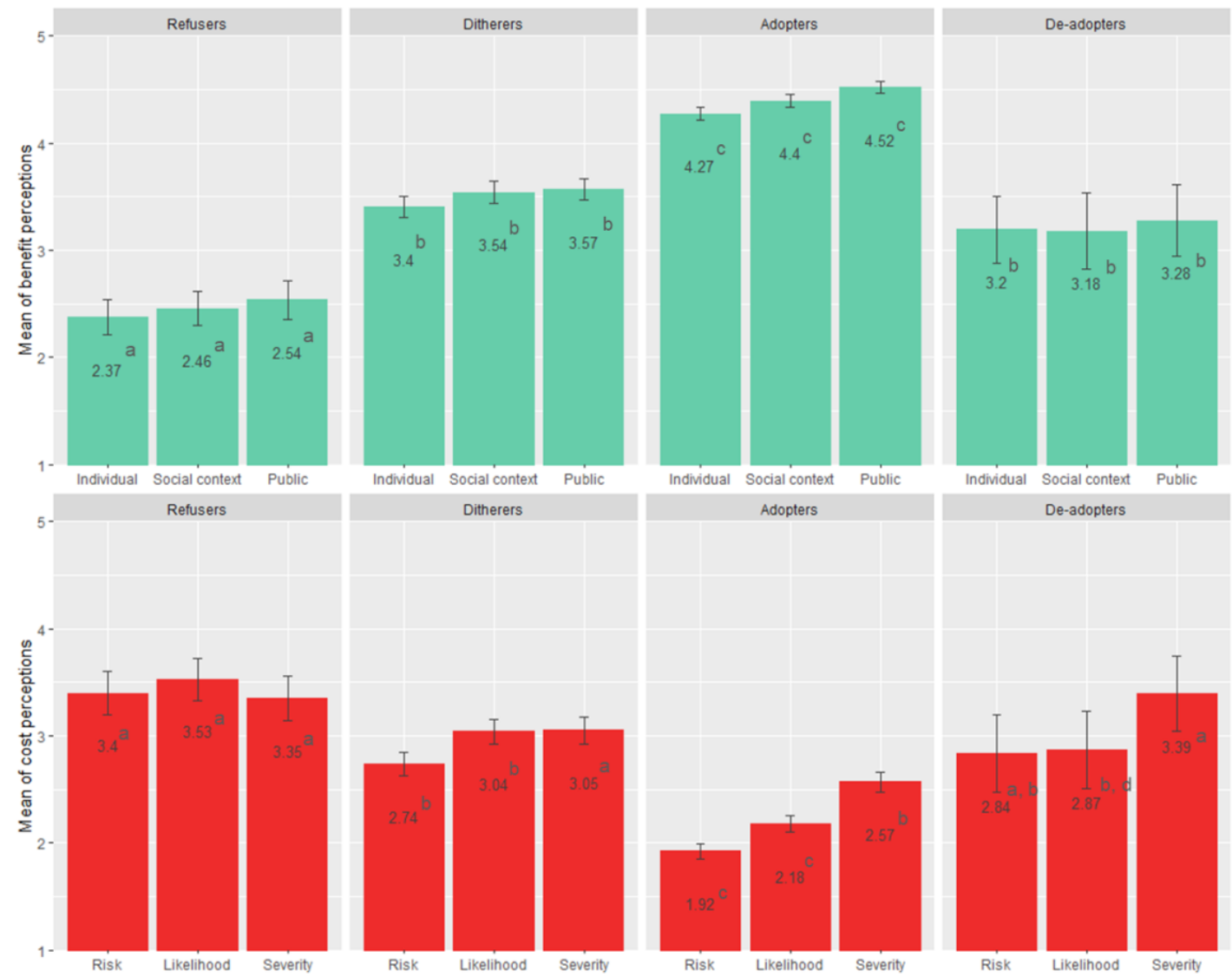

Risk

Likelihood Severity

Figure 2. Perceived health benefits and perceived privacy costs of the types of adopters.

Note. $n=1,480 ; n_{\mathrm{ref}}=203, n_{\text {dith }}=430, n_{\text {adopt }}=786, n_{\text {deadopt }}=61 ;$ scale: $1=$ do not agree at all to 5 = totally agree; Kruskal-Wallis tests: individual health: $H(3)=472.77, p<.001$; health of personal social context: $H(3)=455.61, p<.001$; public health: $H(3)=495.36, p$ $<.001$; risk of data misuse: $H(3)=246.08, p<.001$; likelihood of data misuse: $H(3)=220$, $p<.001$; severity of data misuse: $H(3)=75.3, p<.001$; different subscripts (a, b, c, d) represent significant differences according to the Dunn test with Bonferroni adjustment ( $p$ $<.05)$.

Figure 2 shows that, across all subdimensions (individual health, health of personal social context, public health), adopters rate the health benefits the highest, while refusers rate it the lowest. Pairwise comparisons indicate that both groups differ in this regard from 
each other as well as from the other types of adopters, the ditherers and the de-adopters. The ditherers and de-adopters, however, do not differ in the extent of their perceived benefits. Adopters perceive the risk and likelihood of data misuse the lowest, and refusers, the highest. Again, both types significantly differ from each other and from the other adoption types (the ditherers and de-adopters). The picture is less distinct regarding the perceived severity of data misuse. Refusers, ditherers, and de-adopters assess the consequences of data misuse to be equally severe; only the adopters differ from the other types perceiving the consequences as less severe.

Though the items on perceived benefits and costs are not directly comparable, it is notable that for adopters, the public health benefits outweigh the risk of data misuse, whereas for refusers, the risk of data misuse outweighs the public health benefits. People who hesitate to install the app (ditherers) and people who had installed the app but uninstalled it (refusers) weigh benefits and costs relatively equally.

Table 5. Knowledge Levels of the Types of Adopters.

\begin{tabular}{lllll}
\hline & Refusers & Ditherers & Adopters & De-adopters \\
\hline Knowledge & $M=0.81^{\mathrm{a}}$ & $M=0.98^{\mathrm{a}, \mathrm{b}}$ & $M=1.50^{\mathrm{c}}$ & $M=1.26^{\mathrm{b}, \mathrm{c}}$ \\
& $(S D=0.86)$ & $(S D=0.90)$ & $(S D=0.94)$ & $(S D=0.96)$ \\
\hline
\end{tabular}

Note. $n=1,480 ; n_{\text {ref }}=203, n_{\text {dith }}=430, n_{\text {adopt }}=786, n_{\text {deadopt }}=61 ;$ scale: $0=$ no correct responses to $3=$ three correct responses; Kruskal-Wallis test for knowledge: $H(3)=$ $130.13, p<.001$; different subscripts (a, b, c, d) represent significant differences according to the Dunn test with Bonferroni adjustment $(p<.05)$.

There were also differences among the four types of adopters regarding knowledge on how the tracing app processes data. Table 5 reveals that adopters know the most, and refusers know the least about data collection, storage, and accessibility. Both groups significantly differ from each other but do not have significantly more or less knowledge compared to ditherers and de-adopters. 
Figure 3 displays the distribution of app-related opinion leadership among the four groups of adopters. Adopters have the highest opinion leadership and significantly differ in this respect from the other adoption types. People who had once installed the app but deadopted it later on (de-adopters) range second in opinion leadership; however, they do not significantly differ from ditherers. Refusers show the least opinion leadership.

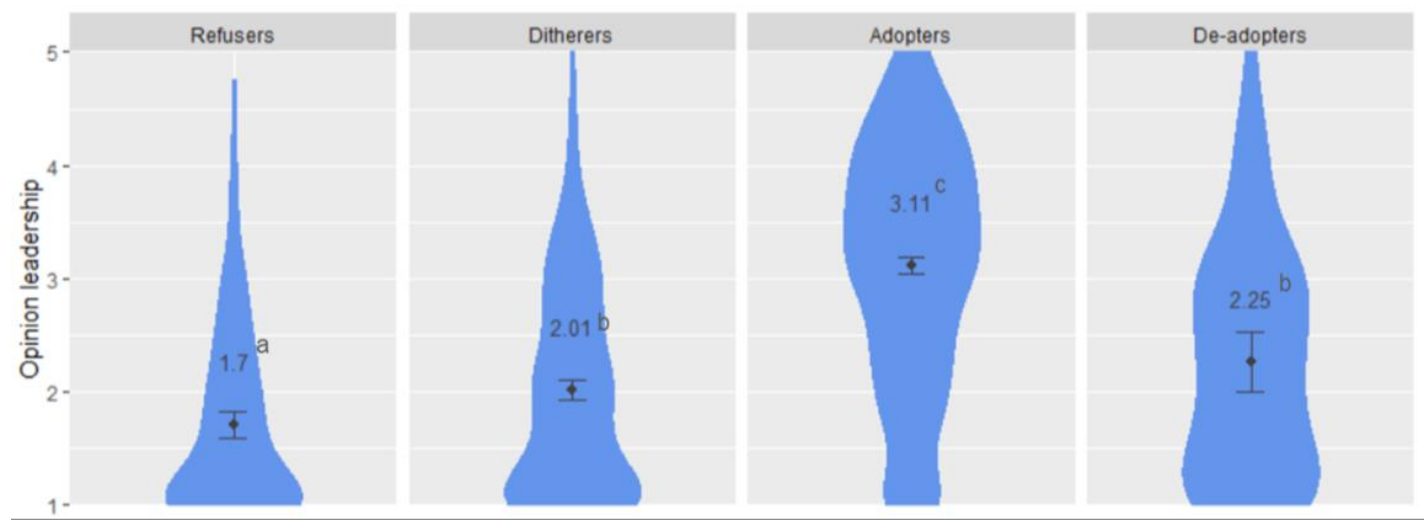

Figure 3. App-related opinion leadership of the types of adopters.

Note. $n=1,480 ; n_{\text {ref }}=203, n$ dith $=430, n_{\text {adopt }}=786, n$ deadopt $=61 ;$ scale $1=n e v e r$ to $5=$ very often; Kruskal-Wallis test for opinion leadership: $H(3)=387.29, p<.001$; different subscripts $(\mathrm{a}, \mathrm{b}, \mathrm{c}, \mathrm{d})$ represent significant differences according to the Dunn test with Bonferroni adjustment $(p<.05)$.

\section{Discussion}

Our typology-based approach to app adoption was meaningful as significant differences were found among the types with regard to their perceptions about app-related benefits and costs, knowledge about data handling in technology, and app-related opinion leadership. In the following, we will summarize and discuss the results for each type.

\section{Types of Tracing-App Adopters}

Refusers. Refusers have not installed the app and have no intention to do so in the future. These people perceive the highest risk of data misuse and, at the same time, the 
lowest public health benefits. It is notable that they are the only group that perceives the risk of data misuse to be higher than the benefit of the app and thus perceive an unfavorable trade-off when it comes to app adoption. Interestingly, this group also knows relatively little about data handling on the app, indicating that their privacy concerns are not well reasoned. As they are not convinced of the utility of the app, it comes as no surprise that refusers do not serve as opinion leaders who promote the use of the app.

Ditherers. In contrast to refusers, ditherers do not generally reject app adoption but hesitate to install and use the app. This adoption type encompasses slightly more women compared to other groups. With regard to all measures under study, they are ranging in the midfield relative to the other groups, which reflects well their uncertainty. They realize the benefits of the app, but, at the same time, perceive to a certain extent the risk of data misuse. Also, they are neither the best nor the worst informed about data handling on the app. Given this uncertainty, it is plausible that ditherers do not act as opinion leaders with regard to the app.

Adopters. Adopters have the highest degree of opinion leadership and seem to see themselves as ambassadors for the app. Adopters are convinced of the public health benefits of the tracing app and do not perceive a risk of data misuse. This means that for them, the app-related benefits outweigh the potential risks of data misuse. They have a relatively high knowledge about data handling on the app, indicating that they are aware of the privacy measures implemented in the app's design.

De-adopters. De-adopters are people who had installed the app but deactivated or uninstalled it afterwards. They are similar to ditherers in many aspects, which makes sense given that their reverted adoption decision indicates some degree of uncertainty. However, they seem to be a bit more knowledgeable with regard to data handling on the app and also show slightly more opinion leadership than ditherers, which may be due to their first-hand experiences of using the app. However, these differences are not statistically significant, mainly because the size of the group of de-adopters is quite small $(n=61)$ and the 
confidence intervals are accordingly large. Thus, these differences should be interpreted with caution.

\section{Implications}

Our typology-based approach follows the call for a profound understanding of app adoption in population subgroups to identify relevant target groups and to ultimately enhance the rate of app adoption through communication strategies (Wyl, Bonhoeffer, et al., 2020). Given the above profiles of the distinct adoption types, communication efforts should focus on the groups of ditherers and adopters. Ditherers are the most promising target group for behavioral change efforts. In contrast to refusers, who are unwilling to adopt the tracing app and thus, may be hard to convince, ditherers are uncertain regarding the adoption of the app. Additionally, the group of ditherers is relatively large compared to other groups, and the app would be more effective if ditherers could be turned into adopters. Adopters, on the other hand, may be the best means to reach out to ditherers as interpersonal communication is powerful in influencing decisions to adopt innovations (Katz, 2015; Katz \& Lazarsfeld, 1955; Rogers, 2002; Southwell \& Yzer, 2009). Also, adopters are app-related opinion leaders, implicating that they can be strategically used to disseminate information about data handling on the app and to convince ditherers of the app's public health benefits. This finding is in line with the diffusion of innovation model (Rogers, 1995), which expects early adopters to have the highest degree of opinion leadership and ditherers to look to opinion leaders for advice and information about the tracing app.

While we suggest focusing communication strategies on ditherers (as potential converts) and adopters (as opinion leaders), further efforts may target refusers to convince them to adopt the app. Given the relatively high extent of privacy concerns in this group and their limited knowledge of data handling on the app, an educational campaign may be an effective strategy (Nowak \& Phelps, 1992). Such a campaign should focus on providing information on how tracing technologies actually work and their public health benefits. In 
this vein, an educational campaign may be able to reduce privacy concerns and to convert refusers at least into ditherers, who show some willingness to adopt the app in the future.

Beyond these type-related implications, our results also indicate the need to improve public perceptions about the benefits of public health while at the same time, reducing privacy concerns. Both perceptions have been shown to play important roles in the adoption process in previous studies; the former promotes, and the latter reduces app adoption (e.g., Hassandoust et al., 2020; Redmiles, 2020). According to this study, the weighting of both factors may be crucial, and in line with the privacy calculus model (Keith et al., 2013; Laufer \& Wolfe, 1977), the perceived public health benefits need to outweigh the perceived risk of data misuse in order for the app to be adopted. A recent study on apprelated reports in Swiss media reveals that the unclarity on the tracing app's effectiveness is one of the major topics in the media (Wyl, 2020). This hampers the widespread diffusion of the app in the Swiss population and demonstrates the need for providing information communication that emphasizes the potential benefits of the SwissCovid app.

The results on respondents' knowledge about how data is processed by the app demonstrate that the Swiss population needs to be educated about the technical aspects of the SwissCovid app. Across all types, the knowledge on the data collection, storage, and accessibility on the app is low. Hence, action is needed, especially as the results indicate an association between knowledge and privacy concerns $(r=-.30)$. The more people know about data handling on the app, the less concerned they are about their privacy. This finding extends the results of previous research on tracing app acceptance that mainly focuses on the role of privacy concerns but does not consider the role of knowledge (Bachtiger et al., 2020; Hassandoust et al., 2020; O'Callaghan et al., 2020; Walrave et al., 2020; Wyl, Höglinger, et al., 2020). 


\section{Limitations}

There are some limitations that need to be considered. The most important limitation is the online mode of the survey, which may produce an overestimation of app adoption. Our data suggest that adopters make up $51.2 \%$ of the Swiss population. Other online surveys conducted in Switzerland report similarly high adoption rates of about $47 \%$ (Wyl, Höglinger, et al., 2020) and 46\% (Brüesch et al., 2020). These numbers are likely an overestimation of actual app adoption in the general population, which is most likely due to the above-average affinity of online panel participants for such technologies. Furthermore, people concerned about privacy may be less likely to take an online survey. However, as the study's primary aim was to learn about the qualitative differences between the types of adopters in terms of their benefit/cost perceptions, knowledge, and opinion leadership and not about the group sizes of the types, this limitation does not concern the study's main aim.

The second limitation is the small size of the de-adopters group $(n=61)$, which is mainly due to the timing of data collection (only one week after the release of the app). Because of the small size of this group, the distinctiveness of the de-adopters is difficult to assess as the confidence intervals are quite large. Thus, statements on the de-adopters' profiles should be made with caution. It may be insightful to explore this group and its reasons for de-adoption in further surveys that are conducted much later after the app's release.

The third limitation deals with the use of self-reports in survey studies, which particularly affects the measurement of opinion leadership and app adoption. The validity of self-designated opinion leadership scales has been questioned (Weimann, 1994), and alternative methods of opinion leader identification have been used in communication research (Valente \& Pumpuang, 2006), such as network analysis-based techniques (Friemel, 2015). However, self-designation scales can be easily administered in surveys and thus combined with other important measures as in the present study. Further, a recent 
observational study suggests that self-designated opinion leadership is actually associated with opinion effects (Geber, 2019). Similarly, tracing-app adoption is also based on selfreports and not on observed data, such as tracing data. Even though the survey was conducted as an anonymous online survey, social desirability may result in over-reporting of app usage. However, given the data security measures built into tracing technologies, there is no way of integrating tracing and survey data on the individual level, which makes survey studies the only feasible way for investigating the adoption of tracing technology.

\section{Conclusion}

The present typology-based approach complements current research on tracing-app adoption as it considers app adoption as a complex phenomenon that encompasses decisions that are not yet made as well as those that have been revised. The differentiation of distinct types of adopters based on their positions in the decision process was insightful. We found differences between the types of adopters concerning their perceptions about health benefits and costs of data misuse, their knowledge about data handling in technology, and their app-related opinion leadership. An advantage of this approach is that findings can be directly translated into implications for communication strategies that aim to enhance the rate of app adoption in the population. Communication efforts should focus on ditherers and adopters; the former are the most promising target group for behavioral change efforts, and the latter seem to be the best means to reach out to ditherers because of their pronounced opinion leadership.

\section{Acknowledgements}

We would like to thank the reviewers and the editors for their valuable feedback on an earlier version of this manuscript. 


\section{Funding}

The research reported in this publication was funded by the Federal Office of Public Health (FOPH); the article is part of Sarah Geber's fellowship within the fellowship program of the Digital Society Initiative (DSI) of the University of Zurich. The FOPH and the DSI had no influence on the decision to publish or on the preparation of the manuscript.

\section{References}

Abuhammad, S., Khabour, O. F., \& Alzoubi, K. H. (2020). COVID-19 contact-tracing technology: Acceptability and ethical issues of use. Patient Preference and Adherence, 14, 1639-1647. https://doi.org/10.2147/PPA.S276183

Altmann, S., Milsom, L., Zillessen, H., Blasone, R., Gerdon, F., Bach, R., Kreuter, F., Nosenzo, D., Toussaert, S., \& Abeler, J. (2020). Acceptability of app-based contact tracing for COVID-19: Cross-country survey evidence. SSRN Electronic Journal. Advance online publication. https://doi.org/10.2139/ssrn.3590505

Bachtiger, P., Adamson, A., Quint, J. K., \& Peters, N. S. (2020). Belief of previous COVID-19 infection and unclear government policy are associated with reduced willingness to participate in app-based contact tracing: A UK-wide observational study of 13,000 patients. MedRxiv: The Preprint Server for Health Sciences. Advance online publication. https://doi.org/10.1101/2020.06.03.20120337

Baruh, L., Secinti, E., \& Cemalcilar, Z. (2017). Online privacy concerns and privacy management: A meta-analytical review. Journal of Communication, 67(1), 26-53. https://doi.org/10.1111/jcom.12276

Bosshardt, L., Bühler, G., Craviolini, J., Hermann, M., \& Krähenbühl, D. (2020). Tracing App des Bundes: Wissen, Einstellungen, Erklärungsfaktoren: Studienbericht zur Bevölkerungsbefragung Federal [Tracing app: Knowledge, attitudes, explanatory factors]. https://www.bag.admin.ch/dam/bag/de/dokumente/cc/Kampagnen/covid19/swisscovid-app-umfragemai2020.pdf.download.pdf/BAG_SwissCovidApp_Befragung_Mai_2020.pdf Brüesch, C., Fischer, D., \& Lang, A. (2020). Bevölkerungsumfrage in der Schweiz, Deutschland und Österreich zur nationalen Contact Tracing-App: Eine Studie des 
Journal of Quantitative Description: Digital Media 1(2021) Typology of Tracing-App Adoption 23

Instituts für Verwaltungs-Management der ZHAW. [Population survey in Switzerland, Germany and Austria on the national contact tracing app: A study by the Institute of Public Management at ZHAW]. ZHAW School of Management and Law. https://www.zhaw.ch/storage/hochschule/medien/news/2020/201119zhaw-studie-corona-app-umfrage.pdf

Cavoukian, A. (2010). Privacy by design: The 7 foundational principles: Implementation and mapping of fair information practices. Information and Privacy Commission. https://iapp.org/media/pdf/resource_center/pbd_implement_7found_principles.pdf

Childers, T. L. (1986). Assessment of the psychometric properties of an opinion leadership scale. Journal of Marketing Research, 23(2), 184-188.

Dinev, T., \& Hart, P. (2006). An extended privacy calculus model for e-commerce transactions. Information Systems Research, 17(1), 61-80. https://doi.org/10.1287/isre.1060.0080

Dunn, O. J. (1961). Multiple comparisons among means. Journal of the American Statistical Association, 56(293), 52-64. https://doi.org/10.1080/01621459.1961.10482090

Federal Office of Public Health. (2020). Coronavirus: Swiss Covid app and contact tracing. https://www.bag.admin.ch/bag/en/home/krankheiten/ausbruecheepidemien-pandemien/aktuelle-ausbrueche-epidemien/novel-cov/swisscovid-appund-contact-tracing.html

Federal Statistical Office. (2019). Population. https://www.bfs.admin.ch/bfs/en/home/statistics/population/effectifchange/population.html

Federal Statistical Office. (2020). SwissCovid-App-Monitoring. https://www.experimental.bfs.admin.ch/expstat/de/home/innovativemethoden/swisscovid-app-monitoring.assetdetail.13407769.html

Ferretti, L., Wymant, C., Kendall, M., Zhao, L., Nurtay, A., Abeler-Dörner, L., Parker, M., Bonsall, D., \& Fraser, C. (2020). Quantifying SARS-CoV-2 transmission suggests epidemic control with digital contact tracing. Science, 368(6491). https://doi.org/10.1126/science.abb6936

Friemel, T. N. (2015). Influence versus selection: A network perspective on opinion leadership. International Journal of Communication, 9, 1002-1022.

Geber, S. (2019). Do self-perceived opinion leaders actually lead opinions? Evidence 
from an observational study on political conversations. Communication Research Reports, 36(3), 209-219. https://doi.org/10.1080/08824096.2019.1598856

Gnambs, T., \& Batinic, B. (2011). Convergent and discriminant validity of opinion leadership. Journal of Individual Differences, 32(2), 94-102. https://doi.org/10.1027/1614-0001/a000040

Guinchard, A. (2020). Our digital footprint under COVID-19: Should we fear the UK digital contact tracing app? International Review of Law, Computers \& Technology, 34(5), 1-14. https://doi.org/10.1080/13600869.2020.1794569

Hargittai, E., Redmiles, E. M., Vitak, J., \& Zimmer, M. (2020). Americans' willingness to adopt a COVID-19 tracking app. First Monday. Advance online publication. https://doi.org/10.5210/fm.v25i11.11095

Hargittai, E., \& Thouvenin, F. (2020). Tracking Per App Findet Breite Zustimmung [Tracking per app finds broad approval]. Neue Züricher Zeitung. https://www.zora.uzh.ch/id/eprint/194425/1/NZZ-20200502Tracking_per_App.pdf

Hassandoust, F., Akhlaghpour, S., \& Johnston, A. C. (2020). Individuals' privacy concerns and adoption of contact tracing mobile applications in a pandemic: A situational privacy calculus perspective. Journal of the American Medical Informatics Association. Advance online publication. https://doi.org/10.1093/jamia/ocaa240

Hinch, R., Probert, W., Nurtay, A., Kendall, M., \& Wymant, C. (2020). Effective configuration of a digital contact tracing app. https://cdn.theconversation.com/static_files/files/1009/Report__Effective_App_Configurations.pdf?1587531217

Kahn, J. (2020). Digital contact tracing for pandemic response: Ethics and governance guidance. Johns Hopkins University Press. https://doi.org/10.1353/book.75831

Kaptchuk, G., Goldstein, D. G., Hargittai, E., Hofman, J., \& Redmiles, E. M. (2020). How good is good enough for COVID19 apps? The influence of benefits, accuracy, and privacy on willingness to adopt. ArXiv: A Preprint Server. https://arxiv.org/abs/2005.04343

Kaspar, K. (2020). Motivations for social distancing and app use as complementary measures to combat the COVID-19 pandemic: Quantitative survey study. Journal of Medical Internet Research, 22(8), e21613. https://doi.org/10.2196/21613 
Journal of Quantitative Description: Digital Media 1(2021) Typology of Tracing-App Adoption 25

Katz, E. (2015). Where are opinion leaders leading us? International Journal of Communication, 9, 1023-1028.

Katz, E., \& Lazarsfeld, P. F. (1955). Personal influence: The part played by people in the flow of mass communications. Free Press.

Keith, M. J., Thompson, S. C., Hale, J., Lowry, P. B., \& Greer, C. (2013). Information disclosure on mobile devices: Re-examining privacy calculus with actual user behavior. International Journal of Human-Computer Studies, 71(12), 1163-1173. https://doi.org/10.1016/j.ijhcs.2013.08.016

Kruskal, W. H., \& Wallis, W. A. (1952). Use of ranks in one-criterion variance analysis. Journal of the American Statistical Association, 47(260), 583-621. https://doi.org/10.1080/01621459.1952.10483441

Lapolla, P., \& Lee, R. (2020). Privacy versus safety in contact-tracing apps for coronavirus disease 2019. Digital Health, 6, 1-2. https://doi.org/10.1177/2055207620941673

Laufer, R. S., \& Wolfe, M. (1977). Privacy as a concept and a social issue: A multidimensional developmental theory. Journal of Social Issues, 33(3), 22-42. https://doi.org/10.1111/j.1540-4560.1977.tb01880.x

Merton, R. K. (1949). Patterns of influence: A study of interpersonal influence and of communication behavior in a local community. In P. Lazarsfeld \& F. N. Stanton (Eds.), Communications research, 1948-1949 (pp. 180-219). Duell, Sloan and Pearce.

Noelle-Neumann, E. (1983). Persönlichkeitsstärke. Ein neues Kriterium zur Zielgruppenbestimmung. In Institut für Demoskopie Allensbach (Ed.), SpiegelDokumentation: Persönlichkeitsstärke: Ein neuer Maßstab zur Bestimmung von Zielgruppenpotentialen [Spiegel documentation: Strength of personality. A new benchmark to define target group potentials] (pp. 7-21). Spiegel Verlag [Strength of personality. A new criterion on target group definition].

Nowak, G. J., \& Phelps, J. (1992). Understanding privacy concerns. An assessment of consumers' information-related knowledge and beliefs. Journal of Direct Marketing, 6(4), 28-39. https://doi.org/10.1002/dir.4000060407

O’Callaghan, M. E., Buckley, J., Fitzgerald, B., Johnson, K., Laffey, J., McNicholas, B., Nuseibeh, B., O'Keeffe, D., O’Keeffe, I., Razzaq, A., Rekanar, K., Richardson, I., Simpkin, A., Abedin, J., Storni, C., Tsvyatkova, D., Walsh, J., Welsh, T., \& 
Glynn, L. (2020). A national survey of attitudes to COVID-19 digital contact tracing in the Republic of Ireland. Irish Journal of Medical Science. Advance online publication. https://doi.org/10.1007/s11845-020-02389-y

R Core Team. (2019). R: A language and environment for statistical computing [Computer software]. R Foundation for Statistical Computing. https://www.Rproject.org/

Redmiles, E. M. (2020). User concerns \& tradeoffs in technology-facilitated COVID-19 response. Digital Government: Research and Practice, 2(1), 1-12. https://doi.org/10.1145/3428093

Rogers, E. M. (1995). Diffusion of innovations (4 ${ }^{\text {th }}$ ed.). Free Press.

Rogers, E. M. (2002). Diffusion of preventive innovations. Addictive Behaviors, 27(6), 989-993. https://doi.org/10.1016/S0306-4603(02)00300-3

Salathé, M., Althaus, C. L., Anderegg, N., Antonioli, D., Ballouz, T., Bugnion, E., Čapkun, S., Jackson, D., Kim, S. I., Larus, J. R., Low, N., Lueks, W., Menges, D., Moullet, C., Payer, M., Riou, J., Stadler, T., Troncoso, C., Vayena, E., \& Wyl, V. von (2020). Early evidence of effectiveness of digital contact tracing for SARS-CoV-2 in Switzerland. MedRxiv: The Preprint Server for Health Sciences. Advance online publication. https://doi.org/10.1101/2020.09.07.20189274

Shapiro, S. S., \& Wilk, M. B. (1965). An analysis of variance test for normality (complete samples). Biometrika, 52(3-4), 591-611. https://doi.org/10.1093/biomet/52.3-4.591

Sharma, S., Singh, G., Sharma, R., Jones, P., Kraus, S., \& Dwivedi, Y. K. (2020). Digital health innovation: Exploring adoption of COVID-19 digital contact tracing apps. IEEE Transactions on Engineering Management, 1-17. https://doi.org/10.1109/TEM.2020.3019033

Southwell, B. G., \& Yzer, M. C. (2009). When (and why) interpersonal talk matters for campaigns. Communication Theory, 19(1), 1-8. https://doi.org/10.1111/j.14682885.2008.01329.x

Straub, E. T. (2009). Understanding technology adoption: Theory and future directions for informal learning. Review of Educational Research, 79(2), 625-649. https://doi.org/10.3102/0034654308325896

Sweeney, Y. (2020). Tracking the debate on COVID-19 surveillance tools. Nature Machine Intelligence, 2(6), 301-304. https://doi.org/10.1038/s42256-020-0194-1 
Journal of Quantitative Description: Digital Media 1(2021) Typology of Tracing-App Adoption 27

Thomas, R., Michaleff, Z., Greenwood, H., Abukmail, E., \& Glasziou, P. (2020). More than privacy: Australians' concerns and misconceptions about the COVIDSafe App. MedRxiv: The Preprint Server for Health Sciences. Advance online publication. https://doi.org/10.1101/2020.06.09.20126110

Trepte, S., \& Scherer, H. (2010). Opinion leaders - Do they know more than others about their area of interest? Communications, 35(2), 119-140. https://doi.org/10.1515/COMM.2010.007

Trepte, S., Teutsch, D., Masur, P. K., Eichler, C., Fischer, M., Hennhöfer, A., \& Lind, F. (2015). Do people know about privacy and protection strategies? Towards the “online privacy literacy scale" (OPLIS). In S. Gutwirth, R. Leenes, \& P. de Hert (Eds.), Reforming European Data Protection Law (pp. 333-365). Springer Netherlands.

Valente, T. W., \& Davis, R. L. (1999). Accelerating the diffusion of innovations using opinion leaders. The ANNALS of the American Academy of Political and Social Science, 566(1), 55-67. https://doi.org/10.1177/000271629956600105

Valente, T. W., \& Pumpuang, P. (2006). Identifying opinion leaders to promote behavior change. Health Education \& Behavior, 34(6), 881-896. https://doi.org/10.1177/1090198106297855

Walrave, M., Waeterloos, C., \& Ponnet, K. (2020). Ready or not for contact tracing? Investigating the adoption intention of COVID-19 contact-tracing technology using an extended unified theory of acceptance and use of technology model. Cyberpsychology, Behavior and Social Networking. Advance online publication. https://doi.org/10.1089/cyber.2020.0483

Weimann, G. (1994). The influentials: People who influence people. State University of New York Press.

Wickham, H. (2016). ggplot2 [Computer software]. Springer. Cham.

Wisdom, J. P., Chor, K. H. B., Hoagwood, K. E., \& Horwitz, S. M. (2014). Innovation adoption: A review of theories and constructs. Administration and Policy in Mental Health, 41(4), 480-502. https://doi.org/10.1007/s10488-013-0486-4

Wyl, V. von (2020). Challenges for non-technical implementation of digital proximity tracing: early experiences from Switzerland. MedRxiv: The Preprint Server for Health Sciences. Advance online publication. https://doi.org/10.1101/2020.10.22.20218057 
Wyl, V. von, Bonhoeffer, S., Bugnion, E., Puhan, M. A., Salathé, M., Stadler, T., Troncoso, C., Vayena, E., \& Low, N. (2020). A research agenda for digital proximity tracing apps. Swiss Medical Weekly, 150, w20324. https://doi.org/10.4414/smw.2020.20324

Wyl, V. von, Höglinger, M., Sieber, C., Kaufmann, M., Moser, A., Serra-Burriel, M., Ballouz, T., Menges, D., Frei, A., \& Puhan, M. A. (2020). Drivers of acceptance of COVID-19 proximity tracing apps in Switzerland. MedRxiv: The Preprint Server for Health Sciences. Advance online publication. https://doi.org/10.1101/2020.08.29.20184382 